\title{
Prevalence of Skin Sensitization to Pollen of Date Palm in Marrakesh, Morocco
}

\author{
Hind Serhane, Lamyae Amro, Hafsa Sajiai, and Abdelhaq Alaoui Yazidi \\ Department of Pulmonology-Allergology, Arrazy Hospital and Mohammed VI University Hospital, PCIM Laboratory, \\ Cadi Ayyad University, Marrakesh, Morocco \\ Correspondence should be addressed to Hind Serhane; hindserhane8@gmail.com
}

Received 27 September 2016; Revised 3 January 2017; Accepted 11 January 2017; Published 8 February 2017

Academic Editor: William E. Berger

Copyright (C) 2017 Hind Serhane et al. This is an open access article distributed under the Creative Commons Attribution License, which permits unrestricted use, distribution, and reproduction in any medium, provided the original work is properly cited.

Background. Date palm's pollen has been identified as a source of allergy; the rate of sensitization of this pollen is between 6 and $29 \%$. Objective. To determine the prevalence of sensitization to date palm in Marrakesh and to identify the clinical profile. Patients and Methods. This study is based on a questionnaire and the prick test on 7 allergens, in population aged 5 years and above with clinical symptoms suggesting allergic diseases, from November 2012 to February 2013 in Marrakech. Results. We included 468 patients (women: 79.5\%). The prick tests were considered interpretable in 467 cases. The prevalence of skin sensitization to pollen of date palm was $6.6 \%$. The 31 cases of sensitization to date palm involved 7 men and 24 women with an average age of 37.5 years. Cutaneous monosensitization to date palm's pollen was observed in 2 cases. Asthma, rhinitis, and conjunctivitis were recorded, respectively, in $48.4 \%, 93.5 \%$, and $67.7 \%$. Conclusion. Skin sensitization to pollen of date palm does not seem unusual among allergic patients in Marrakech and is comparable to that found in Casablanca (7\%), Barcelona (6.6\%), and Cartagena (6.1\%).

\section{Introduction}

Marrakesh palm groves are considered as a historical monument (since early last century, it is the only natural grouping of date palms, located at north of the Atlas Mountains) [1]. Date palm's pollen has been identified as a source of allergy, with sensitization rates among patients with respiratory allergies up to around 13\% in the United Arab Emirates [2], $23 \%$ in Saudi Arabia [3], and from 6\% to $29 \%$ in Spain $[4,5]$. The lack of national and Maghreb data justified the realization of this study to determine the prevalence of sensitization in Marrakesh and to identify the clinical and allergic profile of sensitized patients to date palm.

\section{Patients and Methods}

This is a descriptive cross-sectional study based on a questionnaire and the realization of a prick test (PT) on 7 allergens provided by Stallergenes Laboratory whose references are 315P3-ST for Dermatophagoides pteronyssinus (DP), 314P3ST for Dermatophagoides farinae (DF), 688P3-ST for pollen of the 5 grasses, $651 \mathrm{P} 3$ for olive tree pollen, 626P3 for cypress tree pollen, 668P3 for date palm pollen, and 301P3 for German cockroach. This study was conducted over fourmonth period from 1 November 2012 until the end of February 2013 at Marrakesh in six health centers, located near date palms implantation. We included in the study any patient aged 5 years and more, with clinical symptoms suggesting asthma and/or rhinitis and/or conjunctivitis and/or cutaneous manifestations such as eczema or urticaria. We used the histamine dihydrochloride $(10 \mathrm{mg} / \mathrm{ml})$ as a positive control to ensure skin reactivity and glycerol containing the diluent of the prick test solution as a negative control to eliminate dermographism. We considered a test positive if the wheal diameter obtained was $3 \mathrm{~mm}$ greater than the negative control and/or $50 \%$ greater than the diameter of the positive control. Data analysis was performed by the software Epi Info version 6 , and statistical comparisons were made by the Chi- 2 test.

\section{Results}

In our study, we included 468 patients, 372 women and 96 men with female predominance of $79.5 \%$. The average age 
was $34.9+/-16.5$ years with extremes ranging from 5 to 83 years. Asthma, rhinitis, and conjunctivitis were noted, respectively, in $53.4 \%, 73.7 \%$, and $57.1 \%$. The prick tests were performed in 468 cases and considered interpretable in 467 cases. They are considered positive in 190 cases or $40.7 \%$ of the total studied population. Allergy to pollen of date palm $(6.6 \%)$ came in the sixth skin sensitization after house mite dust (17.9\%), olive tree (12.4\%), German cockroach $(10.5 \%)$, Parietaria in (10.1\%), and cypress tree (9\%) and before the 5 grasses $(6 \%)$. Skin sensitization to different allergens is grouped in Figure 1. Skin sensitization to pollen of date palm was found in 31 patients $(6.6 \%)$. The average age of these patients was 37.5 years (range from 9 to 56 years). The maximum of patients sensitized to the date palm was found in the age group 30-49 years (16 patients) $(p=0.018)$. In fact there is no female predominance because $7.3 \%$ of women sensitized to pollen of date palm against $6.5 \%$ men $(p=$ $0.8) .16$ patients of the $31(51.6 \%)$ sensitized to the date palm reported the presence of date palm tree in their immediate surroundings and only 3 patients were directly exposed to this tree. Cutaneous monosensitization to date palm was noted in only 2 cases, among 29 other patients; skin sensitization was most commonly associated with the cockroach sensitization in 13 cases/29 which corresponds to $44.8 \%$ of cases, with cypress sensitization in 11 cases/29 (37.9\%), with the olive tree sensitization in 9 cases/29 (31.0\%), with the Parietaria sensitization in 8 cases/29 (27.6\%), with the 5grass sensitization in 8 cases/29 (27.6\%), and with the mite in 7 cases/29 (24.1\%). In terms of the clinical history and the physical examination, allergic manifestations were diverse. But it appears that rhinitis was an almost constant symptom and it was found globally in 29 cases/31 (93.5\%) $(p=0.01)$. Asthma was found globally in 15 cases/31 (48.4\%) $(p=0.6)$. Conjunctivitis was found in 21 cases/31 (67.7\%) $(p=0.3)$. Table 1 includes the clinical profile of patients sensitized to pollen of date palm. The asthma symptoms were aggravated by exposure to pollen of date palm in $20 \%$ of cases $(p=0.04)$; this rate was at $23.3 \%$ for rhinitis $(p=0.02)$ and at $23.8 \%$ for conjunctivitis $(p=0.1)$. The average size of the wheal due to the date palm PT was $4.9 \mathrm{~mm}$ (range from 3 to $7 \mathrm{~mm}$ ) against $7.6 \mathrm{~mm}+/-2 \mathrm{~mm}$ for others allergens, in the general population studied.

\section{Discussion}

Different types of studies have focused on determining the prevalence of allergy to pollen of date palm, but the populations were heterogeneous and not well defined. Furthermore, the used allergen extracts were not standardized; we used various allergens and various concentrations. All these factors make it difficult to compare the results of all the work developed significantly. In Spain, five studies have investigated the prevalence of skin sensitization to pollen of date palm in patients with respiratory allergic symptoms or pollinosis. In these patients, the prevalence of skin sensitization was between $6.11 \%$ and $29.41 \%$ [4-8]. In Brussels, in 2006, Mahillon et al. conducted a study on 59 patients followed up for persistent rhinitis and exposed to indoor decorative plants in their own home. They found a
TABLE 1: Clinical manifestations of patients sensitized to pollen of date palms.

\begin{tabular}{lcc}
\hline Clinical manifestations & Number of patients & $\%$ \\
\hline Asthma alone & 1 & 3,2 \\
Rhinitis alone & 4 & 12,2 \\
Conjunctivitis alone & 1 & 3,2 \\
Asthma and rhinitis & 5 & 16,1 \\
$\begin{array}{l}\text { Asthma and } \\
\text { conjunctivitis }\end{array}$ & 0 & 0 \\
$\begin{array}{l}\text { Asthma and rhinitis and } \\
\text { conjunctivitis }\end{array}$ & 9 & 29 \\
$\begin{array}{l}\text { Rhinitis and } \\
\text { conjunctivitis }\end{array}$ & 11 & 35,4 \\
\hline
\end{tabular}

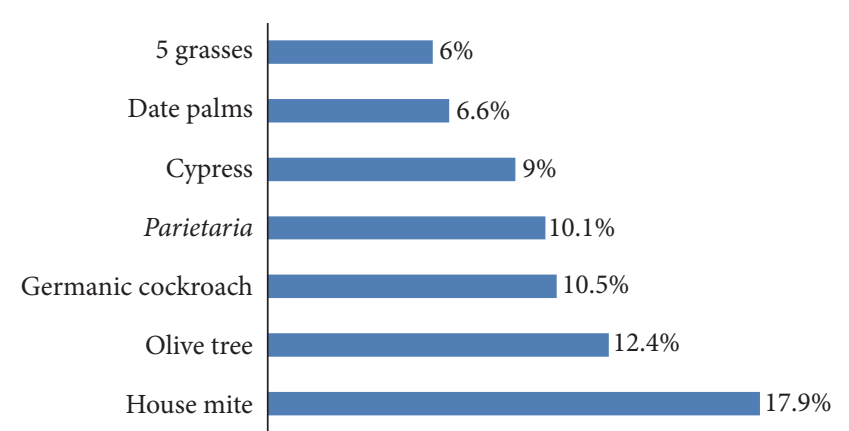

Figure 1: Prevalence of positive skin prick tests to allergens.

prevalence of skin sensitization to palm tree at $10.16 \%$ [9]. In our study, the prevalence of skin sensitization to date palm in patients with rhinitis was $8.4 \%$. In UAE, two studies in $\mathrm{Al}$ Ain city involving patients with respiratory allergic symptoms noted prevalence between $3.6 \%$ and $13.8 \%$ [210]. In Saudi Arabia, Almogren conducted a retrospective study between January 2003 and March 2004, on the analysis of skin testing of patients referred for allergic reactions to the allergy clinic at the King Khalid University Hospital, Riyadh. He found a prevalence of skin sensitization to pollen of date palm at $23 \%$ ( $15 \%$ in adults and $35 \%$ in children) [3]. In our study, the prevalence of skin sensitization to date palms was $7.1 \%$ and $4 \%$, respectively, in adults and children under 15 years. In Vietnam To My and Raffard noted skin sensitization to date palms of $1.9 \%$ in 108 subjects with confirmed asthma living in Ho Chi Minh City [11]. In Algeria, a study by Gharnaout et al. on 82 patients consulting for respiratory allergic symptoms (rhinitis or bronchial asthma and/or conjunctivitis) had found that $16 \%$ of patients had skin sensitization to date palm [12]. In Morocco, a prospective study by Elkhattabi et al. in Casablanca found a prevalence of skin sensitization to pollen of date palm at 7\% [13] which was close to that found in our study in Marrakech. Allergy to date palm can occur at any age. Indeed, the average age of patients sensitized to date palm is variable depending on the population studied (children or adults exclusively or mixed). In the study of Gharnaout et al. conducted in Biskra (Algeria), the average age in patients sensitized to date palm was 34.15 years [12]. Huertas et al. found no statistically significant age 
difference between patients sensitized and not sensitized to pollen of date palm with, respectively, $30.52 \pm 18.45$ years and 27 years \pm 16.86 years [14]. In our study, we noted a female predominance (77.4\%), while Gharnaout et al. noted a male predominance, respectively, in $69.23 \%$ and $54.2 \%$ of cases [12-14]. In all series, rhinitis was the most common clinical manifestation in patients sensitized to pollen of date palm. In fact, it was present in $93.5 \%$ of our patients, $89.02 \%$ of patients in the study of Gharnaout et al. [12], and 97.9\% of patients in the study of Huertas et al. [14]. Conjunctivitis was the most common condition after rhinitis. Gharnaout et al's study established a similar observation with a rate of $63.41 \%$ [12]. In our study, asthma was the least common clinical manifestation in patients sensitized to pollen of date palm with a rate of $48.4 \%$. A similar rate has been reported by Gharnaout et al. (48.78\%) [12]. While Huertas et al.s study found a rate of asthma at $72.9 \%$ in patients sensitized to date palm, it was significantly higher in patients sensitized to date palm than in nonsensitized patients (45.8\%) [14]. Allergy to pollen of date palms is frequently associated with polysensitization [13]. Huertas et al. who were interested in allergic profile of patients sensitized to date palm had found that the distribution of atopic patients by number of pollen sensitization types varied according to the existence or not of the patients sensitized to date palm. $74.51 \%$ of patients with negative skin tests to date palms had under 4 skin sensitization types associated, whereas all patients sensitized to date palm had more than 4 skin sensitization types associated [14]. This could be explained by the fact that sensitization to pollen of date palm in the Mediterranean is an expression of a pan allergen sensitization which is probably a profilin [8]. The same author in another study found that the group of patients sensitized to pollen of date palm had a high sensitization rate to different pollens compared to nonsensitized patients ( 7.25 against 3.31) and this could be a severity indicator of pollinosis in the region, because these polysensitized patients had high risk of bronchial asthma (72.9\% against $45.8 \%)$ [14].

\section{Conclusion}

Allergy to pollen of date palm does not seem to be rare around the Mediterranean basin. Patients sensitized to pollen constitute a homogeneous group of patients characterized by frequent polysensitization and a clinical feature dominated by allergic rhinitis which is the most common clinical manifestation. Therefore, we recommend including the date palm allergen among the routine allergic skin prick tests.

\section{Competing Interests}

The authors declare no conflict of interests.

\section{Authors' Contributions}

All authors have read and approved the final manuscript.

\section{Acknowledgments}

Thanks are due to all the investigators and all doctors in health centers that facilitate that work.

\section{References}

[1] Organisation des Nations Unies Pour l'Alimentation et l'Agriculture, Régénération des Forêts en Algérie, en Egypte, au Maroc et en Tunisie par l'Utilisation d'Eaux Usées Traitées Pour le Soutien des Moyens d'Existence des Petits Agriculteurs et Propriétaires Fonciers, 2012, http://www.fao.org/forestry/35458028dd2e53f9429668bef4d141334f3ed.pdf.

[2] L. Räsänen, "Inhalant allergy in the United Arab Emirates," Allergy, vol. 55, no. 1, pp. 95-96, 2000.

[3] A. Almogren, "Airway allergy and skin reactivity to aeroallergens in Riyadh," Saudi Medical Journal, vol. 30, no. 3, pp. 392396, 2009.

[4] A. J. Huertas, A. Carreño, C. Mérida, M. J. Pajarón-Fernández, M. Ramírez-Hernández, and J. Carnés, "Profilin sensitisation in a Mediterranean population," Allergologia et Immunopathologia, vol. 42, no. 5, pp. 387-394, 2014.

[5] A. J. Huertas, J. M. Mozota, and A. M. García-Cervantes, "Sensibilización a polen de palmera: comparación de suprevalenciaen Zaragoza y Cartagena," Alergología e Inmunología Clínica, vol. 18, pp. 122-123, 2003.

[6] A. Valero, J. Belmonte, and M. Vilardell, Prevalencia de sensibilización a los pólenes de los árboles plantados en la ciudad de Barcelona [Ph.D. thesis], Facultat de Medicina, Universitat Autònoma de Barcelona, 2012.

[7] A. Huertas Amorós, J. Mozota Bernard, and A. García Cervantes, "Prevalencia de sensibilización cutánea a polen de palmera y de morera en el sureste español," Alergologia e Inmunologia Clinica, vol. 17, pp. 193-196, 2002.

[8] A. J. Huertas Amorós, J. R. Lavín Alonso, and A. M. García-Cervantes García, "Es la sensibilización al polen de la palmera una expresión de la alergia a las profilinas en el área mediterránea?" Alergología e Inmunología Clínica, vol. 20, pp. 175-180, 2005.

[9] V. Mahillon, S. Saussez, and O. Michel, "High incidence of sensitization to ornamental plants in allergic rhinitis," Allergy, vol. 61, no. 9, pp. 1138-1140, 2006.

[10] G. Bouix, "Lallergie pollinique dans l'Etat des Emirats Arabes Unis," Revue Française d'Allergologie et d'Immunologie Clinique, vol. 26, no. 2, pp. 59-64, 1986.

[11] H. To My and M. Raffard, "Résultats des tests aux pneumallergènes chez des asthmatiques à Ho Chi Minh ville-Viet Nam," Journal Franco-Vietnamien de Pneumologie, vol. 2, pp. 192, 2011.

[12] M. Gharnaout, R. Abdelaziz, S. Mokhtari, and H. Douagui, "Prévalence de la sensibilisation aux palmiers dattiers dans le sud Algérien (BISKRA)," Revue Française d'Allergologie et d'Immunologie Clinique, vol. 47, article 263, 2007.

[13] W. Elkhattabi, A. Aichane, H. Jabri et al., "Les pollinoses à Casablanca," Revue Française d'Allergologie, vol. 52, pp. 255-262, 2012.

[14] A. J. Huertas, M. P. López-Sáez, and J. Carnés, “Clinical profile of a Mediterranean population sensitised to date palm pollen (Phoenix dactylifera). A retrospective Study," Allergologia et Immunopathologia, vol. 39, no. 3, pp. 145-149, 2011. 


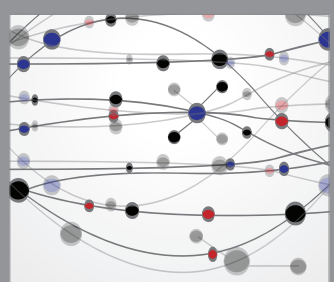

The Scientific World Journal
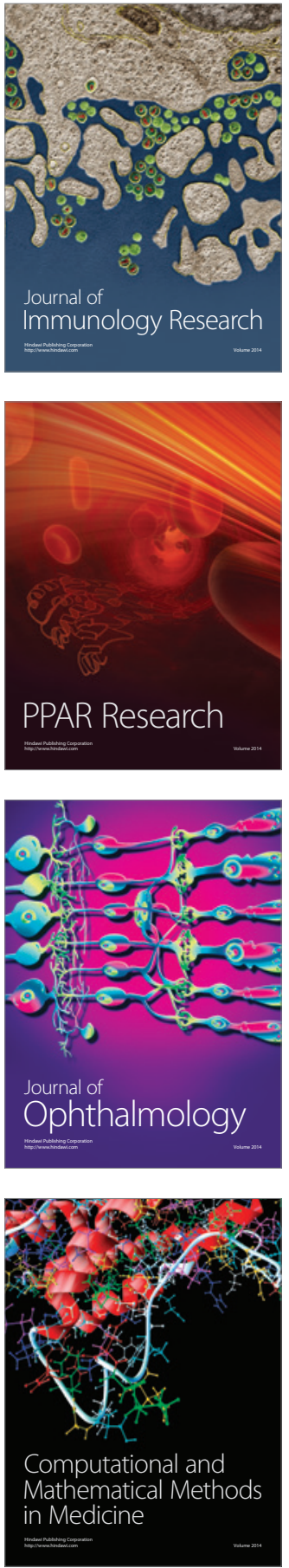

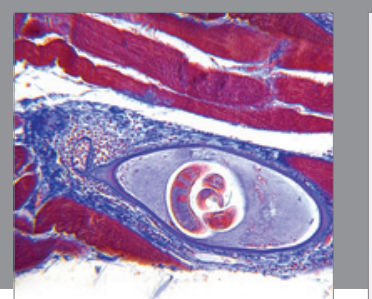

Gastroenterology Research and Practice
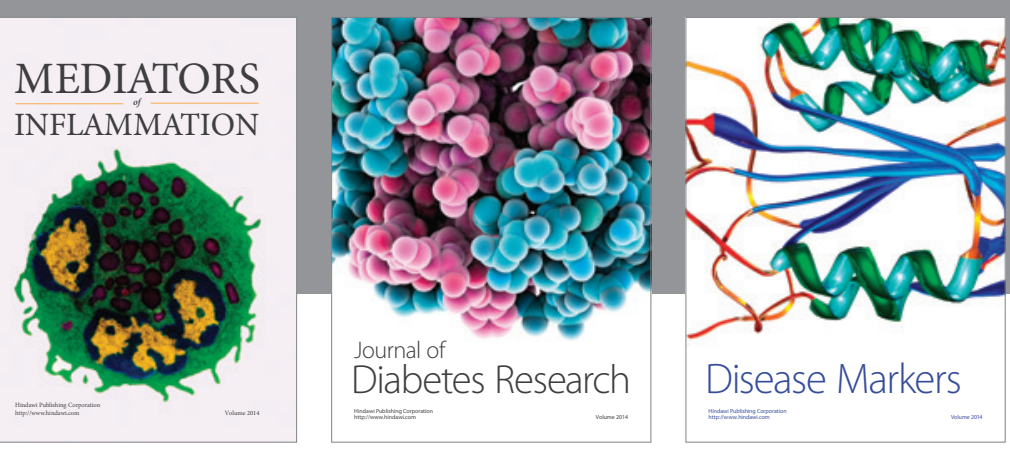

Disease Markers

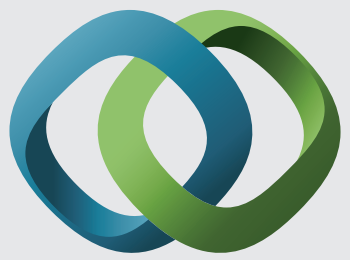

\section{Hindawi}

Submit your manuscripts at

https://www.hindawi.com
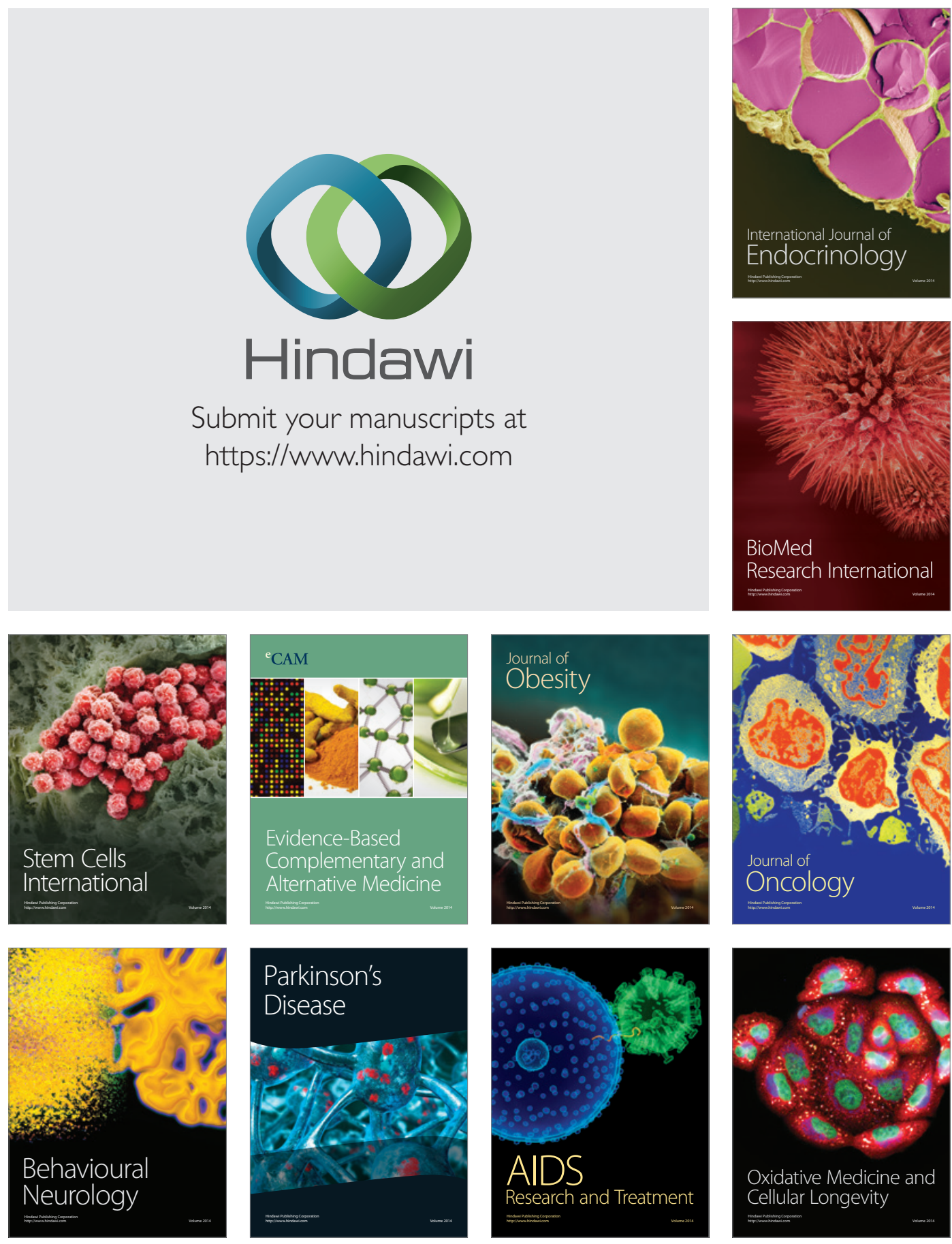